\title{
Lessons from the establishment and maintenance of long-term serial growth studies
}

\begin{abstract}
Alex F. Roche
Abstract

A major focus of the University of Melbourne Child Growth Study and the Fels Longitudinal Study was on the growth and maturation of children. These studies differed in planning, design, logistics and staffing, but each led to exciting analytic opportunities that required longitudinal data. In both studies, there were few publications in the early years, the retention of participants was a major concern, and a balance had to be maintained among the efforts given to the collection, management, and analysis of data. More such studies are needed that focus on particular population groups and topic areas. These new studies should utilize lessons from the past to maximize future success.
\end{abstract}

Key words: Serial studies, children, growth, maturation, cardiovascular disease, genetics

(Japan J. Phys. Educ. 44: 133-151, March, 1999)

\section{Introduction}

In a long-term serial study, the first and last measurements are recorded several or more years apart. In practice, almost all such studies include many variables that are measured on many occasions. Therefore, they differ from follow-up studies in which individuals are measured on only two occasions. A limited number of such studies has been conducted and, to varying extents, they have differed in their effectiveness. The following account describes the establishment and maintenance of the University of Melbourne Child Growth Study (Melbourne Study) and the Fels Longitudinal Study (Fels Study) and directs attention to the opportunities and challenges that they presented. Finally, some future possibilities are discussed.

\section{The Melbourne Study}

The Melbourne Study began in 1954 with an ini- tial funding of $\$ 600 /$ year that increased to $\$ 10,000 /$ year by 1968 . This study included 150 normal children who were aged two years at their first examinations ${ }^{56}$. The enrolled children were almost all second-generation Australians of British ancestry and they were approximately representative of the Melbourne population in socioeconomic status and place of residence. The participants, who were examined at three-month intervals to age four years and thereafter at sixmonth intervals, came for examinations in groups of about five who were the same age and sex. They undressed for photographs and measurements, and wore dressing gowns as they moved between rooms in a busy Anatomy Department. Meanwhile, the mothers talked, became friends, and had an enjoyable visit partly because of the marked continuity of the professional and support staff.

The recorded variables related to size, maturity, nutrient intakes, data from physical, dental 
and orthodontic examinations, and data from radiographs of the hand, knee and foot, and from cephalometric radiographs. Few changes were made in the protocol, but skinfold thickness measurements at five sites were added in 1956. In addition, the same variables were measured serially in special children whose examinations did not necessarily begin at two years and whose serial records varied in length. These special children had trisomy $21(\mathrm{~N}=236)$, large birth weights $(\mathrm{N}=36)$, unusual rates of maturation $(\mathrm{N}=25)$, anisomelia $(\mathrm{N}=177)$, or were short or tall $(\mathrm{N}=547)$.

There were no publications in the first five years of the study because the small staff was overburdened by data collection (Table 1). Later, gradual increases in the staff were accompanied by increases in the number of publications. After the initial years, the staffing included two full-time faculty members who had numerous

Table 1 Number of publications (peer-reviewed journals and book chapters) from the University of Melbourne Child Growth Study (Melbourne) and the Fels Longitudinal Study (Fels) that were based on data from these studies

\begin{tabular}{ccr}
\hline Years & Melbourne & Fels \\
\hline $1929-33$ & - & 2 \\
$1934-38$ & - & 26 \\
$1939-43$ & - & 20 \\
$1944-48$ & - & 20 \\
$1949-53$ & - & 25 \\
$1954-58$ & - & 41 \\
$1959-63$ & 19 & 56 \\
$1964-68$ & 44 & 84 \\
$1969-73$ & 25 & 68 \\
$1974-78$ & 16 & 87 \\
$1979-83$ & 3 & 86 \\
$1984-88$ & - & 113 \\
$1989-93$ & - & 1.02 \\
\hline
\end{tabular}

The Fels publications exclude those concerning behavioral and biocnemical topics. other duties, and five professionals in private practice who assisted for one day per week on a voluntary basis. The Department of Health provided a dentist for one day per week. All these professionals continued to help for at least 12 years.

\section{The Fels Study}

The Fels Study began in Yellow Springs, Ohio in 1929 and was conducted within the Fels Research Institute that was operated by the Fels Fund of Philadelphia ${ }^{43)}$. Additional financial support from the US Government began in the 1950s. In 1977, the Fels Fund transferred the Institute to the School of Medicine at Wright State University in nearby Dayton, Ohio, but continued its financial support until 1982. The Fels Research Institute started with an annual budget of $\$ 5,000$ and a staff of three. By 1968, the staff had increased to about 100 with an annual budget of $\$ 1.4 \mathrm{~m}$, but not all the staff and funding were allocated to the serial study. All the professionals in the Fels Research Institute were full-time research scientists, but they did not devote all their effort to the Fels Study. Because the study was conducted in the small village of Yellow Springs, volunteer research workers were uncommon.

Annually, 10 to 15 participants are enrolled into the study from local families that differ considerably in socioeconomic status (Fig. 1). There are many familial relationships among these participants, almost all of whom are Non-Hispanic Whites. Indeed, this is a study of families and, in some of these families, four generations have been studied since birth. The participants are enrolled before birth and are examined five times in the first year and then every six months until 18 years of age, except that after 1973, the mid-year examinations were omitted from 5 to 10 years for both sexes, and after 16 years for boys and 14 years for girls. Examinations are scheduled at 2- 


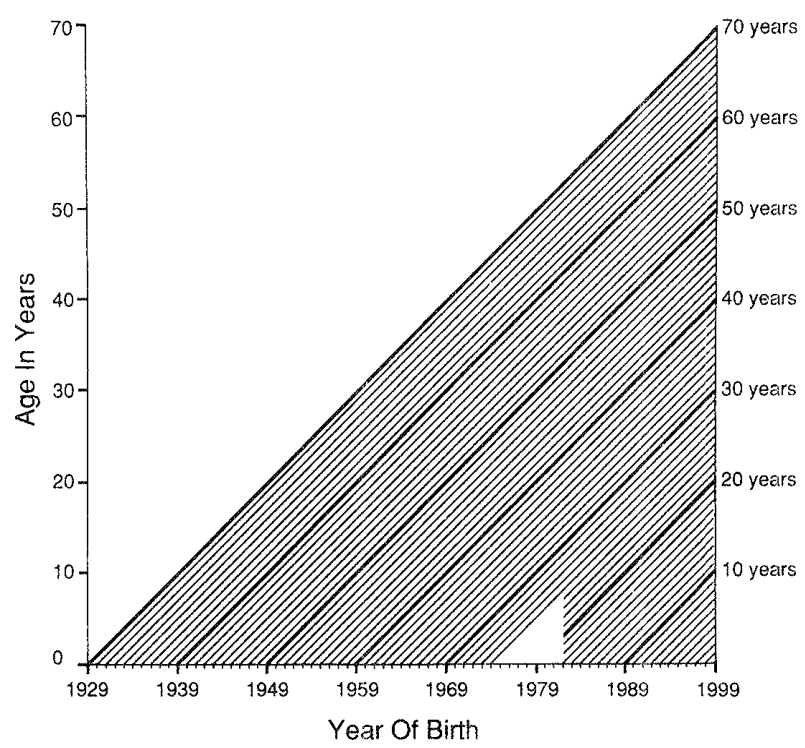

Fig. 1 The design of the Fels Study

year intervals from 18 to 24 years and then at 5 year intervals. The examinations are arranged for individuals, some of whom come with their parents and younger siblings, but there is little communication among participants or their families.

The variables presently recorded relate to size, maturity, body composition, risk factors for chronic diseases, genetic markers, grip strength, physical activity, physical fitness, data from radiographs of the hand, health, menstruation, and the use of tobacco and alcohol. In addition, data were collected previously relating to adipocyte size, hearing ability, somatotypes, personality, school achievement, intelligence, family behavior, fetal movements and nutrient intakes. Various biochemical variables were measured and data were obtained from radiographs of the knee, tibia and head and from physical examinations.

On balance, it was a good decision to locate the Fels Study in the village of Yellow Springs (current population 4,000 ). This village population is more stable in place of residence than is usual in the US; this stability is important for a long-term serial study. Nevertheless, some disadvantages accompanied the relative isolation of the Fels
Study. For example, most departments in the Institute lacked a critical mass of scientists, and it was difficult to obtain effective help from specialists such as biostatisticians. But the Study was, and is, productive. The publication record shows gradual increases until the mid-1950s, when the increases became rapid under the leadership of Dr. Stanley Garn (Table 1). The rate of publication achieved at that time has been maintained or exceeded.

There have been some major changes in the Fels Study during the past 70 years, as is clear from the previous list of types of variables that are no longer collected. In 1947, the upper age limit for examinations was extended from 16 years to 18 years. In the mid-1970s, the upper age limit was removed and measures of total body composition, selected risk factors for disease, hearing ability, and noise exposure were added to the protocol and the behavioral studies were discontinued. A conservative approach to data collection is necessary in the management of a longterm serial study. New variables should be added only if they are biologically related to those already being collected and if their collection will not be too burdensome for the participants and staff. On the other hand, variables being collected should be discontinued when their usefulness is in doubt. For example, adipocyte size was measured from 1979 to 1984, but was discontinued when its utility became unclear. Such decisions may be delayed too long; these delays may be due more to the personalities of research workers than to scientific reasons. This occurred when data relating to fetal movements were collected in the Fels Study for several decades after the analysis of these data had ceased.

Since 1969, there has been considerable collaboration between the Fels Study and the other major US growth studies leading to joint analyses of data. Additionally, there is active collaboration 
with universities in ten US states, US government institutes and agencies, clinics and pharmaceutical companies. Just as major pieces of equipment should be shared, the use of long-term research data should be shared, provided that the research scientists in the long-term study are not relegated solely to data collection.

The Melbourne and Fels Studies differed markedly in quality control. Few replicate data were collected at Melbourne, but staff changes were uncommon. At Fels, replicate data are collected and analyzed routinely and close attention is given to the calibration of equipment. The data from both studies are stored electronically, but data base management is more complex for the Fels Study because there are more variables, more ages at examinations, and a need to document changing familial relationships. In the Fels Study, narrow age tolerances were set around the scheduled ages for examinations. The data recorded outside these age tolerances, about one-third of the total, were not considered useful and were not entered into the data base until about 1970 . Their utility, especially when functions are fitted to study growth patterns and other age changes, is now recognized.

\section{Opportunities}

\section{Methodological studies}

Attention was given in the Melbourne and Fels Studies to possible improvements in data collec. tion methods. In the Melbourne Study, an instru.ment (cyrtographometer) was developed to record breast contours using shadows projected. by parallel light beams ${ }^{60)}$. The long-term goal was to separate changes in size from changes in maturity using data from breast contours, areolar diameters, and stages of breast maturation ${ }^{50)}$. This method of recording body contours has been superseded by stereophotogrammetry, moire contourography and laser stereogrammetry ${ }^{6,7,71)}$. At
Fels, a body volume tank and automatic data entry methods were described in the early $1960 \mathrm{~s}^{11,14,18)}$.

In the Melbourne study, skeletal maturity was assessed using Atlas methods. Analyses were made of the lateral asymmetry of bone-specific hand-wrist skeletal ages, sex-associated differences in skeletal ages, differences between handwrist and knee skeletal ages, and differences between Greulich-Pyle ${ }^{23)}$ and Tanner-Whitehouse ${ }^{70)}$ skeletal ages ${ }^{36,40,48,49)}$. Other analyses were made of the associations between the maturation and elongation of the short bones of the hand ${ }^{41,45,52,53)}$. A major program within the Fels Study led to the development of new methods for the assessment of skeletal maturity ${ }^{44,59)}$. These are the only methods that provide the standard error for each assessment as a guide to the confidence limits of the estimate.

\section{Analyses of serial data}

A major challenge to a serial study is to maximize the information provided by the recorded data. Many such analyses have been made of data recorded in the Melbourne and Fels Studies, but only a few of these will be described. Other analyses of data from the Fels Study have been described by Roche ${ }^{43)}$.

Some statistical methods used in analyses of serial Fels data had not been applied previously to data relating to growth. It is interesting, in relation to the evolution of the Fels Study, to consider the methodological differences between three sets of reference data for increments derived from Fels data. Robinow ${ }^{35)}$ reported means and SDs of increments during infancy for males and females combined without adjusting for variations in the lengths of the intervals between measurements. In 1980, Roche and Himes ${ }^{54)}$ published percentiles of 6 -month increments for each sex from birth to 18 years after demonstrating 
the absence of seasonal effects and adjusting the observed data to exact target ages using fastFourier transforms. More recently, reference data for increments have been derived by fitting a function to the serial data for each individual and using this function to interpolate to target ages ${ }^{51)}$. With the latter approach, the same individuals are used for each interval and the empirical percentiles do not require smoothing.

\section{Bone elongation and stature}

One Melbourne analysis was based on the identification of fixed trabecular patterns from radiographs of metacarpals ${ }^{37)}$. Measurements from these patterns showed that about $25 \%$ of the elongation of the diaphyses from 2 to 11 years occurred at their non-epiphyseal ends. Since the first metacarpal has a single epiphysis at its proximal end and the second metacarpal has a single epiphysis at its distal end, differential elongation at the two ends of these diaphyses was accompanied by distal migration of the diaphysis of the first metacarpal relative to that of the second metacarpal. Similar conclusions were reached from measurements of the first and second metatarsals.

Analyses in the Melbourne Study showed that the stature deficit in children with trisomy 21 , expressed in $z$ scores, did not increase with age ${ }^{38)}$. Surprisingly, the statures of these children did not increase after mean ages of 15.5 years for males and 14.3 years for females, although their skeletal ages indicated that potential for growth in stature still remained.

Using Fels data, parametric functions have been developed that describe growth in body length for which the general patterns of growth are similar among individuals despite differences in intercepts, rates of growth, and the timing of critical events ${ }^{4,5,72)}$. These parametric functions were used to define biological landmarks on the growth curves that have been used in genetic analyses (see later). For similar purposes, non-parametric functions have been fitted to variables, such as body mass index (BMI; weight/stature ${ }^{2}$ ), that do not have fixed patterns of change with age ${ }^{64)}$.

The final phase of growth in stature has been described using piecewise regressions fitted to serial data for individuals ${ }^{42,46)}$. The Fels data are suitable for such analyses, in contrast to many growth studies in which retention was poor during the older teenage years, and data collection stopped at 18 years. In the Fels analyses, a polynomial function was fitted to the earlier data and a horizontal line was fitted to the later data for each participant. After identifying the age (junction) at which the goodness of fit was maximal for the two functions combined, it was estimated that adult stature was reached at median ages of 21.2 years for males and 17.3 years for females with ranges of about six years between the 10th and 90th percentiles. In females, growth in stature continued for almost five years after menarche with a median increase in stature of $7.9 \mathrm{~cm}$ during this time. The increments in stature after menarche were negatively correlated $(r=-0.5)$ with the age of menarche and there was a similar relationship with age at peak height velocity in each sex (Fig. 2).

At Fels, a method was developed for the prediction of adult stature because parental concern is common and there can be clinical concern, if the present statures of children are unusual ${ }^{58)}$. Recumbent length was preferred to stature as a predictor because recumbent length can be measured in infancy and in childhood and stature can be adjusted to recumbent length by adding 1.25 $\mathrm{cm}^{47)}$. In retrospect, this was an unwise decision since there is little need for predictions of adult stature during infancy and the differences between recumbent length and stature are study- 

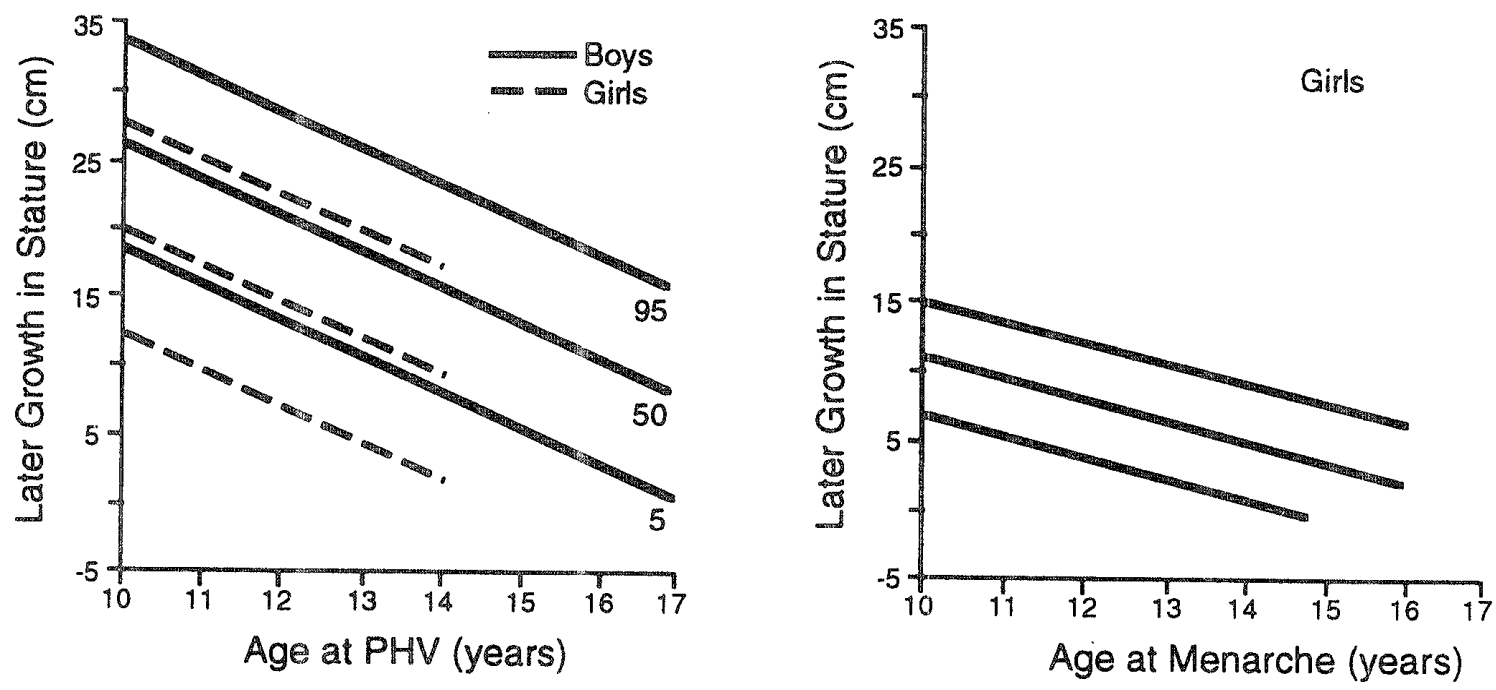

Fig. 2 Percentiles of the total increments in stature after peak height velocity and menarche in relation to the ages at which these events occurred ${ }^{42)}$; reproduced from Growth, Genetics and Hormones; with permission)

specific. The other predictors chosen were the present weight, Greulich-Pyle ${ }^{23)}$ hand-wrist skeletal age of the child, and the mean of the sta. tures of the parents (mid-parent stature). The coefficients of age- and sex-specific regression equations were made orthogonal, smoothed across age, and then transformed back to their original relationships. This smoothing allowed interpolations to each month of age. The accuracy of the predictions of adult stature from this method was assessed from the differences between the actual and the predicted adult statures (residuals). The 95th percentiles of the residuals were about $5.0 \mathrm{~cm}$ at most ages in each sex in the validation group and on cross-validation in the Berkeley, Denver and Harvard Growth Studies. Subsequently, it was shown that substitution of Fels skeletal ages ${ }^{44)}$ for Greulich-Pyle skeletal ages reduced the residuals and the method was modified so that it can be applied in the absence of skeletal age data. This modified method can provide a non-invasive measure of maturity ${ }^{57)}$.

\section{Indices of overweight}

Cronk and colleagues ${ }^{9,10)}$ used longitudinal principal components to describe changes in BMI during growth. This procedure, which is applied to an intercorrelation matrix for one variable at multiple ages, yields components that are common to all individuals, but each individual has a specific age-invariant coefficient for each component. There are strong correlations between the patterns of change in BMI during growth and BMI values at 30 years ${ }^{9)}$. In males, about half the variance in BMI at 30 years is explained by the coefficients for Components 1 and 2 (general level; slope) for 10 to 17 years in combination, but components for infancy explain little of the variance.

Polynomial functions were fitted to log-transformed serial BMI data from 2 to 18 years for individuals to obtain accurate estimates of the timing and extent of inflections ${ }^{64)}$. The good fit allowed the calculation of the minimum value and age at minimum value, the maximum value and age at maximum value, and maximum velocity. Each of these estimates is positively correlated 

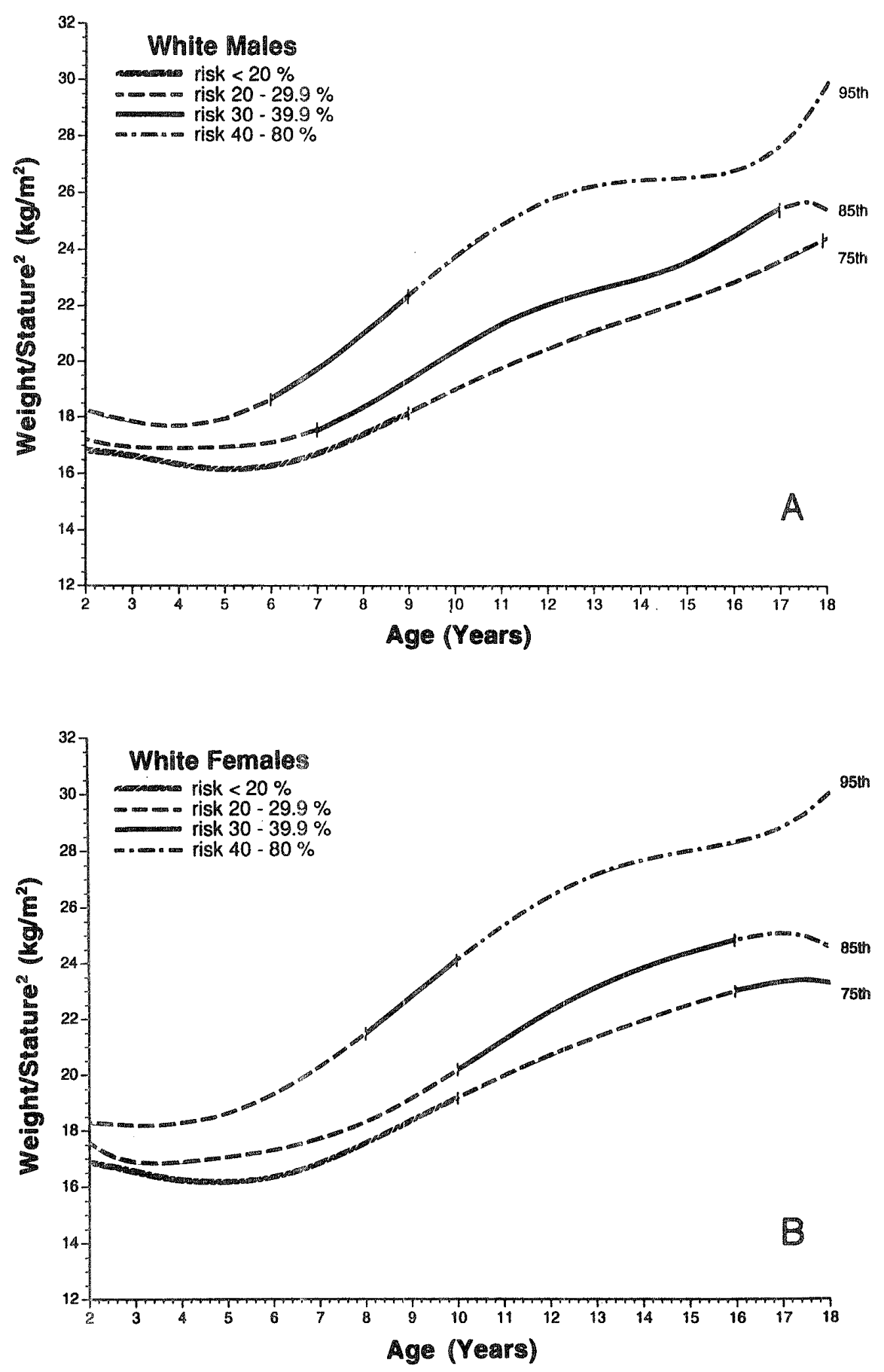

Fig. 3 Graphs for White males (Fig. 3A) and for White females (Fig. 3B) that show the 75th, 85th and 95th BMI (W/S ${ }^{2}$ ) percentiles from the Second National Health and Nutrition Examination Survey (US; 1976-1980). These percentile lines are differentially shaded to indicate the estimated probabilities of BMI values at 35 years that exceed $28 \mathrm{~kg} / \mathrm{m}^{2}$ for males and $26 \mathrm{~kg} / \mathrm{m}^{2}$ for females ${ }^{26)}$; reproduced from Am. J. Clin. Nutr.; with permission)

with BMI values at 18 years, except that the correlations are negative for the ages at the minimum value and the correlations are not sig- nificant for ages at maximum velocity.

Guo and coworkers ${ }^{26)}$ used logistic regressions to estimate the predictive value of childhood BMI 
for overweight at 35 years, defined as BMI $>28$ $\mathrm{kg} / \mathrm{m}^{2}$ for men and $>26 \mathrm{~kg} / \mathrm{m}^{2}$ for women. These predictions are excellent at 18 years and good at 13 years, but less accurate at ages younger than 13 years. A clinically applicable method was developed that allows an overweight child to be assigned to a group with a known range of probabilities for high BMI values in adulthood (Fig. 3). This method is known to be applicable only to US Non-Hispanic Whites. The recorded BMI value should be plotted on the sex-appropriate chart where the probability of overweight at 35 years is indicated by differential shading of the percentile lines.

A linear model was used to analyze the tracking of plasma lipoproteins from 9 to 21 years ${ }^{25)}$. This model allowed (i) the intervals between measurements to be unequal, (ii) some data to be missing, (iii) the tracking coefficients to vary with the lengths of the intervals, and (iv) inclusion of all the available data in one analysis for each varia. ble. For intervals of 4 to 12 years, the coefficients are higher for total cholesterol and LDL. cholesterol ( $r=0.6$ to 0.8$)$ than for HDL. cholesterol ( $r=0.3$ to 0.6 ) and they decrease slightly as longer intervals are considered. Esti. mates were made of the probabilities of being in moderate or high-risk groups for lipoprotein levels at 19 to 21 years, conditional on the values at nine years. As expected, the probabilities increase with the initial level and they are larger for adulthood values that indicate a moderate risk than for those that indicate a high risk.

Age-to-age correlations from a damped autoregressive model have been reported for blood pressures ${ }^{1)}$. The coefficients are generally low $(r=0.1$ to 0.4$)$, but they tend to be higher than those reported by others, perhaps due to the use of mean values when there were multiple examinations during an age range. These age-to-age correlations, which are similar for systolic and di- astolic pressures, tend to decrease slightly as longer intervals are considered, but they are not closely related to the ages at the first measurements. Other analyses estimated the relative risk of high diastolic pressure $(>90 \mathrm{mmHg})$ at 35 years conditional on diastolic pressure at 15 years. The risks, relative to diastolic pressure $=60 \mathrm{mmHg}$ at 15 years, are higher for females than for males and increase markedly with increases in diastolic pressure at 15 years.

\section{Familial and genetic analyses}

The Fels Study did not begin with a genetic component, but, through a mix of happenstance and convenience at the beginning, and purposeful intent soon after, the Fels Study has become increasingly suitable for genetic analyses. Most of the mothers who enrolled their children in the late 1920s and early 1930s had more children later. Having had pleasant experiences with the Fels Study during the course of their older child's participation, and having received for those children, in the midst of the Great Depression, free physical examinations and health care advice, many asked if their subsequent children could participate. Also, a few years after the beginning of the Study, a set of triplets was recruited specifically to examine their similarities in growth and development ${ }^{34)}$. Another set of triplets and a few twin pairs were likewise especially recruited in later years. Thus, for its size, the Fels Study has slightly more triplets and twins than probably would have been the case under strict random sampling.

Over time, other relatives were incorporated into the Study, the first of these being the offspring of Study participants. Later, as increasing numbers of Study participants started their own households, the spouses who were not serial study participants were asked to come for at least one examination. Entirely new families were 
recruited into the Study until the early 1970s, but since then the emphasis has been on recruiting relatives of existing participants. The Fels Study today has more than 1,000 participants with serial data from infancy, and cross-sectional data from more than 2,000 of their primarily adult relatives. Altogether, there are about 200 kindreds, consisting of both nuclear and extended families.

The opportunities afforded by the familial nature of many of the Fels Study data were recognized early. The description of a "Genetics Program" component of the Fels Study by Sontag in $1946^{66)}$ is remarkable for its content and modern sounding tone. Sontag noted that many aspects of growth and development were likely to have significant genetic determination, but are influenced by environmental factors as well. He stated that the Fels Study included many families with two or more children and that these "... constitute the material for the study of inheritance of growth patterns as well as of metabolic characteristics." Although most of the genetic studies conducted at Fels over the years have dealt with aspects of growth and development, these genetic investigations have been highly varied in type and timing, reflecting the interests and training of particular investigators, the familial data available, the prevailing analytic methods, and collaborations with researchers at other institutions.

In the early years of the Study, the set of monozygotic dichorionic triplets mentioned earlier was the subject of four reports that described their physical and mental traits as young children, striae in their bones, the onset of ossification from infancy through pubescence, and growth and maturation as these triplets became young adults ${ }^{67-69)}$. A paper by Reynolds ${ }^{33)}$ is especially noteworthy because it used familial data from different types of relatives to examine the effects of degree of kinship on patterns of ossification. Included in this study were the set of identi- cal triplets mentioned above, three pairs of identical twins, 22 pairs of siblings, eight pairs of first cousins, and 18 unrelated children. Reynolds found that close relatives were very similar in pattern of ossification, distant relatives less so, and unrelated even less similar.

The amount of familial data steadily increased so that by the 1950s investigators were able to examine, with sufficient sample sizes, patterns of familial correlations in a variety of traits. Most notable are a series of papers from the late 1950s to the late 1960s in which Garn and colleagues examined patterns of familial correlations in traits pertaining especially to dental and skeletal maturation. Although nuclear familial correlation studies, like twin studies, cannot definitively separate genetic from shared environmental (household) effects, they can be used to at least provisionally identify traits that may be heritable, and that may be transmitted in Mendelian fashion. An example of the analyses and sample sizes from this period is provided by Garn and associates $^{22)}$ who examined ossification data from radiographs of the hand-wrist and chest for 72 parent-child pairs, 318 sibling pairs, four pairs of dizygotic twins, and four pairs of monozygotic twins. Since these were serial data taken at halfyearly intervals from ages one to seven years, there were 1,211 pairings of parent-child data, 6,690 pairings of sibling data, 102 pairings of data from dizygotic twins and 176 pairings of data from monozygotic twins. These authors concluded that, "In these well-nourished . . Ohio-born white children, genes appear to account for a major proportion of ossification variance during growth." These investigators also examined the genetics of various dental traits including the timing of stages of dental development ${ }^{16)}$, tooth morphology $y^{17)}$, and the appearance of discrete dental traits ${ }^{15)}$. The influence of familial factors on growth in body size also were examined ${ }^{12,19,21)}$. 
Following difficult administrative and scientific changes during the 1970s, the Fels Study became the centerpiece of the new Division of Human Biology at Wright State University School of Medicine and its focus shifted to the establishment of the Fels Study as a valuable resource for the investigation of risk factors for cardiovascular disease (CVD) over the life span. Genetic studies of growth and development were not a high priority during these years. This situation changed rapidly in the early 1980 s, however, as investigators in the Division and elsewhere recognized the opportunities in the extensive familial data on growth and development that had been collected. Also, with the recognition by the 1980s of significant genetic involvement in obesity, and the unequivocal establishment of obesity as a major CVD risk factor, the Study proved a thoroughly unique resource for examining the genetics of the development of CVD risks. For example, Siervogel and colleagues ${ }^{63)}$ found significant familial resemblance for the changes in the body mass index (BMI) from 2 to 18 years. This analysis was made possible by serial data from family mem. bers in multiple generations. These types of data do not exist in any other study.

Fels investigators have taken advantage of: these unique data, and the tremendous advances in statistical and molecular genetics, to examine in detail the genetics of growth and development, body composition, and various CVD risk factors in childhood and in adulthood. For example, Towne et a1. ${ }^{73)}$ fitted a three-parameter function to serial recumbent lengths from 569 infants and found heritabilities of 0.83 for recumbent length at birth, 0.67 for rate of increase in length, and 0.78 for a parameter describing the curvilinear shape of growth in recumbent length from birth to two years. More recently, the triple logistic model of Bock et al. ${ }^{2)}$ was fitted to serial stature data for 471 Fels Study participants in 188 kin- dreds and a multivariate quantitative genetic analysis of pubertal growth pattern parameters was conducted $^{76)}$. Highly significant heritabilities on the order of 0.85 for age at peak height velocity, 0.61 for growth rate at peak height velocity, and 0.96 for stature at the age of peak height velocity were found. Especially interesting was the finding of additive genetic correlations between these pubertal growth spurt parameters that were significantly lower than 1.0; this suggests incomplete pleiotropic effects of genes on different aspects of growth. That is, different growth curve parameters may have unique genetic bases. Furthermore, some provisional evidence of associations between specific genetic polymorphisms in the human growth hormone/chorionic somatomammotropin gene cluster at chromosome 17q:23-24 and growth patterns has been found ${ }^{74,75)}$.

In studies pertaining more directly to public health concerns about the high prevalence of deaths from CVD, the magnitude of the shared genetic underpinnings of different CVD risk factors has been examined. Towne et al. ${ }^{77)}$ found a moderately low heritability (0.29) for fasting insulin concentration, a moderately high heritability for BMI (0.53), and a genetic correlation between them of 0.59 . The latter finding indicates that fasting insulin concentration and BMI are jointly influenced by only some of the same genes. It was also found that the positive pleiotropic effects of genes on BMI and blood pressure become more pronounced after pubescence $^{78)}$. Additionally, sex differences in the heritability of blood pressure before and after puberty have been examined ${ }^{80)}$.

\section{Difficulties and Challenges}

The preceding descriptions of the Melbourne and Fels Studies include few references to the difficulties and challenges presented by them. 
These will be considered now in relation to recruitment and retention, secular changes, changes and continuity in methods of measurement, and funding.

\section{Recruitment and Retention}

The number of participants recruited should be sufficient to allow analyses that have the statistical power to demonstrate real effects. It is difficult to perform meaningful power analyses when a long-term study is being designed since many of the future analyses will not be foreseen. The recruitment process should aim to enroll participants who, as far as possible, are representative of the population group to be studied. It is difficult to recruit an ethnic group into a longterm serial study if the group is small in number or the group members consider themselves discriminated against by society. These difficulties can be overcome by hiring members of the same ethnic group to work in the study, by eliciting the help of leaders within the ethnic community, and by convincing members of the ethnic group that they will benefit from the study. This process is expensive and slow, but it is possible ${ }^{24)}$.

The enrollment for long-term studies of special children may be through residential or day-care institutions ${ }^{31,39)}$. The children in these institutions may not be representative of special children with the same diagnosis in the general population. Even if a representative sample is enrolled, the sample examined may not be representative. Children with an intercurrent infection at the time of a scheduled examination are not likely to attend, and such infections are common in some groups of special children. It is difficult to obtain some records in particular groups. In the Melbourne Study, cephalometric radiographs of individuals with trisomy 21 could be obtained of only about $30 \%$ of children aged less than ten years and of about $80 \%$ of adults.
Retention is critical for any long-term study. It is necessary to retain professional staff, support staff, and participants. The Melbourne and Fels Studies have been very successful in the retention of professional and support staff. The basic need is to unite both groups into a single team in which there is mutual respect and a shared view that their contributions are worthwhile. To reach this goal, the leader must remember what it was like to be a recent graduate and the senior support staff must remember their needs when they first became members of the study team. There is a need to balance hierarchical control, autonomy and cooperation. This is sometimes difficult. Both professional and support staff should have opportunities for career enhancement and intellectual development, freedom of expression, and full access to the recorded data for analytic purposes; and they should be prepared to change when necessary. The professional staff must do more than manage and work in the study. They must keep in touch with societal needs and research opportunities.

Some data relating to retention are given in $\mathrm{Ta}$ ble 2. Retention in the Fels Study was assisted by some special circumstances. A parent, and com-

Table 2 The percentage retention in the Fels and Paris Studies (all enrolled at birth)

\begin{tabular}{|c|c|c|c|c|c|}
\hline \multirow{2}{*}{ Growth phases } & \multicolumn{5}{|c|}{ Ages (mo) } \\
\hline & 3 & 6 & 9 & 24 & 36 \\
\hline \multicolumn{6}{|l|}{ Infancy } \\
\hline $\begin{array}{l}\text { Fels Longitudinal Study } \\
\text { (births 1985-1992) }\end{array}$ & 94 & 96 & 96 & 94 & 91 \\
\hline \multirow{3}{*}{ Paris Study (62) } & 一 & - & 75 & 65 & 59 \\
\hline & \multicolumn{5}{|c|}{ Ages (yr) } \\
\hline & 16 & 17 & 18 & 20 & 22 \\
\hline \multicolumn{6}{|l|}{ Post-Puberty } \\
\hline $\begin{array}{l}\text { Fels Longitudinal Study } \\
\text { (births 1968-1974) }\end{array}$ & 97 & 84 & 97 & 67 & 56 \\
\hline Paris Study $(62)$ & 20 & 15 & 10 & 3 & - \\
\hline
\end{tabular}


Table 3 Factors related to retention in the Melbourne, Fels and Paris Studies

\begin{tabular}{lccc}
\hline \multicolumn{1}{c}{ Factors } & Meibourne & Fels & Paris \\
\hline $\begin{array}{l}\text { Long-term faculty \& } \\
\text { staff }\end{array}$ & yes & yes & yes \\
$\begin{array}{l}\text { Transportation } \\
\text { provided or } \\
\text { reimbursed }\end{array}$ & no & yes & no \\
$\begin{array}{l}\text { Gifts/Stipends } \\
\text { Physical examinations }\end{array}$ & yes & after 1970 & no \\
Newsletters & yes & after 1975 & yes \\
Individual booklet & yes & no & no \\
Annual picnic & yes & no & no \\
\hline
\end{tabular}

monly a grandparent, of all infants born in 1985-1997, and most of those born in 1968-1984, has been included in the Fels Study since birth, and invasive procedures are not used before eight years of age. These advantages may have been somewhat offset by the termination of physical examinations and pediatric advice in 1973. Table 2 provides comparative data from a study conducted in Paris by Sempé and his associates ${ }^{62)}$. In the Paris study, the retention rate was lower than in the Fels Study. The protocol for the Paris study in. cluded physical examinations but not invasive procedures. Many factors may have contributed to the differences in retention rates, including the absence of a previous commitment to the study by the parents of these Parisian children.

Table 3 lists some design factors in the Melbourne, Fels and Paris Studies that affect the retention of participants. During infancy, retention depends more on interactions with the mother than with the infant. Retention is more difficult for mothers who are teenagers, single or have a language barrier. If the purpose of the study makes it necessary to include such mothers, they should receive individual attention.

Continuity of the professional and support staff: who have direct personal interactions with the participants or their families is very important.
Ideally, the same few staff members will manage the examinations and will develop cordial relationships with each mother. Travel expenses should be paid and the infant or child should receive a gift at each examination. In the Melbourne Study, funding was insufficient to allow such payments and gifts. In the Fels Study, stipends were not paid before 1970; they were considered unnecessary because the families regarded the physical and psychological examinations as major benefits. The number of examinations should not exceed what is necessary, and a mother should be greeted warmly and receive immediate attention when she arrives with her child for an examination. Accompanying siblings should be made welcome and play facilities should be provided for them.

Mothers who understand the aims and the potential benefits of the study to society and to their infant or child are more likely to remain interested and continue their participation. This requires verbal explanations supplemented by a booklet that describes the study. One excellent way to encourage continued participation is to give the mother photographs of her child that she can place in this booklet. Selected data from each examination should be sent to the mother or older child including notations of unusual values that may be of clinical significance. The fathers should be involved through newsletters and functions, such as picnics, to which all family members are invited.

The management of the infant or child has a major effect on retention. Invasive procedures should be kept to a minimum and occur only after other procedures. It is impossible to obtain accurate measurements of a participant who is upset because a blood sample has just been obtained. Similarly, participants who are hungry or thirsty require attention to the cause of their distress before they are measured. 


\section{Secular changes}

In any long-term study, secular changes may reduce the relevance of findings from analyses that relate data collected several decades ago to data collected recently. Secular changes can be documented; they cannot be prevented.

Secular changes were not present within the Melbourne Study because a single cohort was enrolled, but secular changes in the general population may have affected the applicability of some of the findings. In the Fels Study, the annual enrollment of small groups allows analyses of possible secular changes within the study. Small nonlinear secular changes are present in Fels data for recumbent length, weight, stature and tibial length ${ }^{8,13,27)}$. Pubescent spurts in head circumference now occur earlier and the maximum rate of growth during this spurt has increased ${ }^{55)}$.

Bock and Sykes ${ }^{3)}$ found increases in stature between Fels parents and their offspring measured at corresponding ages during growth. The contrast between the marked continuing secular in-crease in stature within families and small in. creases in the total Fels data set is largely due to the recruitment after 1940 of families in which the adult statures are smaller than those for the families recruited earlier. In another approach to the analysis of possible secular changes, the parameters of functions fitted to serial data for weight and length of individual infants were regressed on year of birth and on (year of birth) ${ }^{2}$ 29,30). Prior to 1940 , birth weight was decreasing, the pattern of growth in weight was becoming more curvilinear, and the rate of growth in recumbent length was decreasing; these tendencies were reversed after 1952 .

There has not been a secular change in the timing of onset of ossification for the bones of the hand-wrist in the Fels Study, and there are only small differences in knee skeletal ages within parent-offspring pairs of the same sex when both are assessed at the same chronological age $\mathrm{e}^{20,59)}$.

\section{Changes and continuity in methods of measurement}

Advances in data collection methods that become available during a serial study provide opportunities that must not be ignored. Improved methods may be added to the protocol or they may replace previous methods. In the Fels Study, densitometry, impedance, ultrasound, photon absorptiometry and hydrometry have been added. Such additions should be made only if the burden for participants will not reduce compliance and if the new data can enhance the data base and allow more effective analyses. If a new method becomes available that may replace an older method, some other considerations apply. The new and previous methods may putatively provide data for the same biological variable, e.g., caliper and ultrasonic measurements of subcutaneous adipose tissue. Replacement of the previous method by the new method requires considerable testing, documentation of differences, and a period of overlap. Additionally, the timing of examinations requires periodic review. In the Fels Study, examinations at half-birthdays are now omitted from five to ten years in boys and from five to eight years in girls.

\section{Funding}

Funding will be discussed first in relation to the initiation of new long-term studies and later in relation to the continuation of funding for existing studies. The remarks that follow apply in particular to the US, but it is expected that many of them are equally applicable to Japan.

Although an investigation similar to the Fels Study has not been started in the US since 1932, major European studies were commenced in Amsterdam, Leuven and Nymegen between 1967 and $1973^{28,32,65)}$. A person wishing to begin a new 
study could learn a great deal from the leaders of these investigations. It is important to consider the possibility of simpler, more-focused designs, such as a US study of teenage pregnancies that has extended for more than ten years ${ }^{61)}$.

It is difficult to obtain funding for any new large study. A possible approach is to extend a cross-sectional study, or a short-term serial study, by adding more examinations and by including a genetic component. Funding success requires a design with the potential to answer questions of public health relevance or biological importance that cannot be answered more quickly and more cheaply from studies with simpler designs. Funding agencies must be convinced that the sample will be large enough to provide statistical significance and sufficiently representative to provide results that are widely applicable. They are likely to give particular attention to the leadership of the study, because this will be a major factor in its success. Effective leadership is based on example in regard to sustained effort, clear thinking, and the recruitment of good staff that are welded into one team that includes both the professional and support staff. All members of the team should receive recognition for unusual efforts and for continued good performance.

Funding for the continuation of a long-term study is dependent on the use of current methods, the importance of the research, and documentation that secular changes have not reduced the relevance of the data collected early in the study. The major key to continued funding, however, is the frequent publication of serial analyses in peerreview journals.

\section{The Future of Long-Term Serial Studies}

Some suggestions can be made about the future of long-term serial studies. The inclusion of new methods may allow more effective analyses of the associations of data recorded at young ages and chronic diseases and physical fitness in adulthood. New non-invasive methods that should be considered for inclusion include echocardiography, the measurement of carotid artery wall thickness, the measurement of body volume by air displacement or laser stereophotogrammetry, and molecular genetic analyses. A major priority is collaboration among studies that may relate to data collection and analysis or the processing of laboratory samples, e.g., skeletal age assessments, molecular genetic analyses.

Future analyses of serial data will vary in importance with the significance of the hypotheses, the nature of the databases, and the effectiveness of the statistical methods that are applied. The statements that follow relate specifically to the Fels Study, but they are applicable to many other studies. The most significant hypotheses will be those that are relevant to public health and clinical practice or to biological issues and they will relate to sets of variables for which convincing serial analyses are lacking. There will be limited interest in repeating previous analyses with similar data sets, but replication analyses are justified when databases become available that include more participants, extend over longer age ranges, or are derived from special groups.

Not all the statistical methods need be new. The current methods have served us well and their use should continue. For example, statistical models, that are suitable for the particular data, should be applied to univariate serial data based on fitting person-specific curves to summarize the general shapes of the curves over time (the mean structure), differences in curves from person to person (the between-person covariances), and the extent to which individuals follow their own predicted curves over time (within-person correlation or tracking). The data may relate to growth-related variables, risk factors for diseases, or physiological variables. 
Incomplete data are common in long-term studies due to variations in adherence to the timing of scheduled examinations, missed examinations, attrition and, perhaps, variations in age at entry. The longer the study, the greater the extent to which the data will be incomplete and the larger the number of parameters that can be estimated. It is important, however, to apply methods that produce few parameters so that parsimonious correlation structures can be obtained that better represent the correlations among serial measures.

Since many interrelated variables are recorded in long-term studies, multivariate serial analyses are needed to investigate the relationships between variables in their patterns of change. Thus, measures at an age and patterns of change for the size, proportions and composition of the body, risk factors for disease, life style measures, and physiological variables are interrelated. Covariates should be incorporated into univariate and multivariate models; these covariates may be constants or they may vary with time. Parental risk factors which are constant, such as stature, should be considered for inclusion as covariates in serial models to study familial and genetic associations. The inclusion of modifiable risk factors, including the usual dietary intake, habitual physical activity, and cigarette smoking, as covariates will increase understanding of the patterns of change that are demonstrated by multivariate serial analyses. To make the findings useful, the descriptions of complex statistical procedures should be made understandable by non-statisticians and the results should be presented in formats that facilitate their application.

At least in the Fels Study, genetic analyses will play an increasing role. Recently, the quantitative genetics of hand-wrist skeletal ages from the Fels Method $^{44)}$ have been investigated. Towne et al. ${ }^{79)}$ found the heritability of relative skeletal age (skeletal age/chronological age) at age nine years to be 0.85 , and at 15 years to be 0.59 . The additive genetic correlation between relative skeletal age at nine and 15 years, however, was 0.67 ; a value significantly less than 1.0 which indicates only partial pleiotropic effects of genes on skeletal maturity at pre- and post-pubertal ages. This study is one component in a set of collaborative initiatives presently underway that will expand our studies of the genetics of growth and development. The goal is to locate and identify quantitative trait loci that influence skeletal maturation. This work will use Fels skeletal ages for more than 15,000 hand-wrist-radiographs and more than 7,000 knee radiographs of children who have participated in the Fels Study since 1932. Beginning in 1991, DNA samples have been obtained from the participants and their relatives. High resolution genomic marker maps will be constructed for each Study participant, and modern linkage analysis methods will be employed to scan the genomes for marker variants linked to various indices of skeletal maturity at specific chronological ages throughout childhood. Additionally, a number of candidate genes that are responsible for various clinical disorders will be examined to see if normal allelic variants exist and, if so, their associations with quantitative variation in indices of normal skeletal maturation will be determined. Exciting possibilities exist.

The opportunities for new long-term serial studies extend to all ages and ethnic groups, and to special groups such as those with particular diseases or genetic defects. Some such studies should focus on groups that have high risks of chronic disease, but not high risks of early death. The decision to include children with trisomy 21 in the Melbourne Study greatly improved the scientific and public image of the study and added to its effectiveness. The need exists, the methods exist, and success can be attained with focused 
efforts and persistence.

\section{References}

1) Beckett, L. A., Rosner, B., Roche, A. F., and Guo, S. (1992) Serial changes in blood pressure from adolescence into adulthood. Am. J. Epid. 10: 1166-1177.

2) Bock, R. D., du Toit, S. H. C., and Thissen, D. (1994) AUXAL: Auxological Analysis of Longitudinal Measurements of Human Stature. Scientific Software International: Chicago, IL.

3) Bock, R. D. and Sykes, R. C. (1989) Evidence for continuing secular increase in height within families in the United States. Am. J. Hum. Biol. 1: 143148.

4) Bock, R. D. and Thissen, D. (1980) Statistical problems of fitting individual growth curves. in Human Physical Growth and Maturation: Methodologies and Factors. eds. Johnston, F. E., Roche, A. F. and Susanne, C.: 265-290. Plenum: New York.

5) Bock, R. D., Wainer, H., Petersen, A., Thissen, D., Murray, J., and Roche, A. F. (1973) A parameterization for individual human growth curves. Hum. Biol. 45: 63-80.

6) Bradtmiller, B. (1996) Sizing head forms: Design and development. Technologies for Occupant Protection Assessment. SP-1174: 107-114.

7) Burke, P. H. (1971) Stereophotogrammetric measurement of normal facial asymmetry in children. Hum. Biol. 43: 536-548.

8) Byard, P. J. and Roche, A. F. (1984) Secular trend for recumbent length and stature in the Fels Longitudinal Growth Study. in Human Growth and Development. eds. Borms, J., Hauspie, R., Sand, A., Susanne, C. and Hebbelinck, M.: 209214. Plenum Press: New York.

9) Cronk, C. E., Roche, A. F., Chumlea, W. C., and Kent, R. (1982) Longitudinal trends of weight/ stature $^{2}$ in childhood in relationship to adulthood body fat measures. Hum. Biol. 54: 751-764.

10) Cronk, C. E., Roche, A. F., Kent, R., Berkey, C., Reed, R. B., Valadian, I., Eichorn, D., and McCammon, R. (1982) Longitudinal trends and continuity in weight/stature ${ }^{2}$ from 3 months to 18 years. Hum. Biol. 54: 729-749.

11) Garn, S. M. (1962) Automation in anthropometry. Am. J. Phys. Anthrop. 20: 387-388.
12) Garn, S. M., Clark, A., Landkof, L., and Newell, L. (1960) Parental body build and developmental progress in the offspring. Science. 132: 15551556.

13) Garn, S. M. and French, N. Y. (1967) Magnitude of secular trend in the Fels population: Stature and weight. Private Printing.

14) Garn, S. M. and Helmrich, R. H. (1967) Next step in automated anthropometry. Am. J. Phys. Anthrop. 26: 97-100.

15) Garn, S. M., Lewis, A. B., Kerewsky, R. S., and Dahlberg, A. A. (1966) Genetic independence of Carabelli's trait from tooth size or crown morphology. Arch. Oral Biol. 11: 745-747.

16) Garn, S. M., Lewis, A. B., and Polacheck, D. L. (1960) Sibling similarities in dental development. J. Dent. Res. 39: 170-175.

17) Garn, S. M., Lewis, A. B., and Walenga, A. J. (1968) The genetic basis of the crown-size profile. J. Dent. Res. 47: 1190.

18) Garn, S. M. and Nolan, P., Jr. (1963) A tank to measure body volume by water displacement (BoVoTa). N.Y. Acad. Sci. Annal. 110: 91-95.

19) Garn, S. M. and Rohmann, C. C. (1966) Interaction of nutrition and genetics in the timing of growth and development. Ped. Clin. North Amer. 13: 353-379.

20) Garn, S. M. and Rohmann, C. G. (1959) Communalities of the ossification centers of the hand and wrist. Am. J. Phys. Anthrop. 17: 319-323.

21) Garn, S. M. and Rohmann, C. G. (1967) "Midparent" values for use with parent-specific, age-size tables when paternal stature is estimated or unknown. Ped. Clin. North Amer. 14: 283.

22) Garn, S. M., Rohmann, C. G., and Davis, A. A. (1963) Genetics of hand-wrist ossification. Am. J. Phys. Anthrop. 21: 33-40.

23) Greulich, W. W. and Pyle, S. I. (1959) Radiographic Atlas of Skeletal Development of the Hand and Wrist, 2nd Ed. Stanford University Press: Stanford, CA.

24) Grunbaum, J. A., Labarthe, D. R., Ayars, C., Harrist, R., and Nichaman, M. Z. (1996) Recruitment and enrollment for Project Heartbeat!: Achieving the goals of minority inclusion. Ethnicity, Dis. 6: 203-212.

25) Guo, S., Beckett, L., Chumlea, W. C., Roche, A. F., and Siervogel, R. M. (1993) Serial analysis of 
plasma lipid and lipoproteins from 9 to 21 years. Am. J. Clin. Nutr. 58: 61-67.

26) Guo, S. S., Chumlea, W. C., Roche, A. F., Siervogel, R. M., and Gardner, J. D. (1994) The predictive value of childhood body mass index. values for overweight at 35 years. Am. J. Clin. Nutr. 59: 810-819.

27) Hertzog, K. P., Garn, S. M., and Hempy, H. O., III (1969) Partitioning the effects of secular trend and ageing on adult stature. Am J Phys Anthrop. 31: 111-116.

28) Kemper, H. C. G. (1995) The Amsterdam Growth Study. A Longitudinal Analysis of Health, Fitness, and Lifestyle. HK Sport Science Monographs Series. Vol. 6. pp. iii-278, Human Kinetics: Champaign, IL.

29) Kouchi, M., Mukherjee, D., and Roche, A. F. (1985) Curve fitting for growth in weight during, infancy with relationships to adult status, and familial associations of the estimated parameters. Hum. Biol. 57: 245-265.

30) Kouchi, M., Roche, A. F., and Mukherjee, D. (1985) Growth in recumbent length during infancy with relationships to adult status and familial associations of the estimated parameters. Hum. Biol. 57: 449-472.

31) Milani, S., Signorile, F., Benso, A., and Gilli, G. (1996) Problems in auxological monitoring of chronic diseases. Acta Med. Auxol. 28: 25-37.

32) Prahl-Andersen, B., Kowalski, C. J., and Heydendael, P. (1979) A Mixed-Longitudinal Interdisciplinary Study of Growth and Development. pp. v-771, Academic Press: New York.

33) Reynolds, E. L. (1943) Degree of kinship and pattern of ossification. Am. J. Phys. Anthrop. 1: 405416.

34) Reynolds, E. L. and Schoen, G. (1947) Growth patterns of identical triplets from 8 through 18 years. Child Development. 18: 130-151.

35) Robinow, M. (1942) The variability of weight and height increments from birth to six years. Child Develop. 13: 159-164.

36) Roche, A. F. (1962) Lateral comparisons of the skeletal maturity of the human hand and wrist. Am. J. Roentgenol. 89: 1272-1280.

37) Roche, A.F. (1965) The sites of elongation of human metacarpals and metatarsals. Acta Anat. 61: 193-202.
38) Roche, A. F. (1965) The stature of mongols. J. Ment. Defic. Res. 9: 131-145.

39) Roche, A. F. (1967) Difficulties associated with studies of growth and development in mentally retarded children. Proc. 1st Congr. Int. Assoc. Scientific Study Ment. Defic., Montpellier.: 845-852.

40) Roche, A.F. (1968) Sex-associated differences in skeletal maturity. Acta Anat. 7: 321-340.

41) Roche, A. F. (1970) Associations between the rates of maturation of the bones of the hand-wrist. Am. J. Phys. Anthrop. 33: 341-348.

42) Roche, A.F. (1989) The final phase of growth in stature. Growth, Genetics \& Hormones. 5: 4-6.

43) Roche, A. F. (1992) Growth, Maturation and Body Composition: The Fels Longitudinal Study 1929-1991. pp. xiii +282, Cambridge University Press: Cambridge, UK.

44) Roche, A. F., Chumlea, W. C., and Thissen, D. (1988) Assessing the Skeletal Maturity of the Hand-Wrist: Fels Method. pp. 339, Charles C Thomas: Springfield, IL.

45) Roche, A. F. and Davila, G. H. (1970) Associations between the rates of maturation and growth in the short bones of the hand. Am. J. Phys. Anthrop. 33: 349-356.

46) Roche, A. F. and Davila, G. H. (1972) Late adolescent growth in stature. Pediatrics. 50: 874-880.

47) Roche, A. F. and Davila, G. H. (1974) Differences between recumbent length and stature within individuals. Growth. 38: 313-320.

48) Roche, A. F., Davila, G. H., and Eyman, S. L. (1971) A comparison between Greulich-Pyle and Tanner-Whitehouse assessments of skeletal maturity. Radiology. 98: 273-280.

49) Roche, A. F. and French, N. Y. (1970) Differences in skeletal maturity levels between the knee and hand. Am. J. Roentgenol. 109: 307-312.

50) Roche, A. F., French, N. Y., and Davila, G. H. (1971) Areolar size during pubescence. Hum. Biol. 43: 210-223.

51) Roche, A. F., Guo, S., and Moore, W. M. (1989) Weight and recumbent length from 1 to 12 mo of age: Reference data from $1-$ mo increments. Am. J. Clin. Nutr. 49: 599-607.

52) Roche, A. F. and Hermann, R. F. (1970) Associations between the rates of elongation of the short bones of the hand. Am. J. Phys. Anthrop. 32: 83- 
88.

53) Roche, A. F., Hermann, R. F., and Davila, G. H. (1970) Correlations between the rates of epiphyseal and diaphyseal elongation in the short bones of the hand. Am. J. Phys. Anthrop. 33: 31-35.

54) Roche, A. F. and Himes, J. H. (1980) Incremental growth charts. Am. J. Clin. Nutr. 33: 20412052.

55) Roche, A. F., Mukherjee, D., and Guo, S. (1986) Head circumference growth patterns: birth to 18 years. Hum. Biol. 58: 893-906.

56) Roche, A. F. and Sunderland, S. (1959) Melbourne University Child Growth Study. Med. J. Austr. i: 559-562.

57) Roche, A. F., Tyleshevski, F., and Rogers, E (1983) Non-invasive measurement of physical maturity in children. Res. Quart. Exer. Sport. 54: 364-371.

58) Roche, A. F., Wainer, H., and Thissen, D. (1975) Predicting Adult Stature for Individuals. pp. 1114, Monographs in Paediatrics, Vol. 3, Karger: Basel.

59) Roche, A. F., Wainer, H., and Thissen, D. (1975) Skeletal Maturity: The Knee Joint as a Biological Indicator. Plenum Publishing Corporation: New York.

60) Roche, A. J. and Wignall, J. W. G. (1962) The cyrtographometer: A new instrument for recording contours. Am. J. Phys. Anthrop. 20: 521-525.

61) Scholl, T. O. and Hediger, M. L. (1995) Weight gain, nutrition, and pregnancy outcome: Findings from the Camden Study of teenage and minority gravidas. Seminars Perinat. 19: 171-181.

62) Sempé, M., Pédron, G., and Roy-Pernot, M. P. (1979) Auxologie. Méthode et Séquences. pp. , Laboratoire Théraplix: Paris.

63) Siervogel, R. M., Mukherjee, D., and Roche, A. F. (1984) Familial resemblance for patterns of change in weight/stature $\left(\mathrm{W} / \mathrm{S}^{2}\right)$ from 2 to 18 years. Am. J. Hum. Genet. 36: 180S.

64) Siervogel, R. M., Roche, A. F., Guo, S., Mukherjee, D., and Chumlea, W. C. (1991) Patterns of change in weight/stature ${ }^{2}$ from 2 to 18 years: Findings from long-term serial data for children in the Fels Longitudinal Growth Study. Int. J. Obes. 15: $478-485$

65) Simons, J., Beunen, G. P., Renson, R., Claessens,
A. L. M., Vanreusel, B., and Lefevre, J. A. V. (1990) Growth and Fitness of Flemish Girls. The Leuven Growth Study. HKP Sport Science Monogr. Series Vol. 3. pp. iii-173, Human Kinetics Books: Champaign, IL.

66) Sontag, L. W. (1946) The Fels Research Institute for the Study of Human Development. Antioch College: Yellow Springs, OH.

67) Sontag, L. W. and Comstock, G. (1938) Striae in bones of a set of monozygotic triplets. Am. J. Dis. Child. 56: 301-308.

68) Sontag, L. W. and Nelson, V. L. (1933) A study of identical triplets Part I. Comparison of the physical and mental traits of a set of monozygotic dichorionic triplets. J. Hered. 24: 473-480.

69) Sontag, L. W. and Reynolds, E. L. (1944) Ossification sequences in identical triplets. A longitudinal study of resemblances and differences in the ossification patterns of a set of monozygotic triplets. J. Hered. 35: 57-64.

70) Tanner, J. M., Whitehouse, R. H., and Healy, M. J. R. (1962) A new system for estimating skeletal maturity from the hand and wrist, with standards derived from a study of 2,600 healthy British children. II. The scoring system. pp., International Children's Centre: Paris.

71) Terada, H. (1974) A new apparatus for stereometry: Moire contourograph. in Nutrition and Ma1nutrition: Identification and Measurement. eds. Roche, A. F. and Falkner, F.: 27-72. Plenum Press: New York.

72) Thissen, D., Bock, R. D., Wainer, H., and Roche, A. F. (1976) Individual growth in stature: A comparison of four growth studies in the U.S.A. Ann. Hum. Biol. 3: 529-542.

73) Towne, B., Guo, S., Roche, A. F., and Siervogel, R. M. (1993) Genetic analysis of patterns of growth in infant recumbent length. Hum. Biol. 65: 977-989.

74) Towne, B., Parks, J. S., Brown, M. R., Murphy, T., and Siervogel, R. M. (1993) Measured genotype analysis of a Bgl II chorionic somatomammotropin RFLP and adult stature. Am. J. Hum. Genet. 53: 1666.

75) Towne, B., Parks, J. S., Brown, M. R., Murphy, T., and Siervogel, R. M. (1993) Measured genotype analysis of age at peak height velocity and a Bgl II chorionic somatomammotropin RFLP. 
Genetic Epidemiol. 10: 343.

76) Towne, B., Parks, J. S., Guo, S., and Siervogel, R. M. (1995) Quantitative genetic analysis of associations between pubertal growth spurt parameters. Am. J. Hum. Genet. 57: A173.

77) Towne, B., Roche, A. F., Chumlea, W. C., and Siervogel, R. M. (1995) Quantitative genetics of fasting plasma insulin and body mass index in adults. Circulation. 91: 22 .

78) Towne, B., Roche, A. F., Chumlea, W. C., and
Siervogel, R. M. (1996) Genetics of blood pressure and body mass index before and after puberty. Circulation. 93: 623.

79) Towne, B., Roche, A. F., Parks, J. S., Blangero, J., and Siervogel, R. M. (1996) Quantitative genetics of pre- and postpubertal skeletal maturity. Am J Hum Genet. 59: A191.

80) Towne, B. and Siervogel, R. M. (1997) Heritability of blood pressure in boys and girls before and after puberty. Circulation. 94: I-691. 